\title{
Foco de criptas aberrantes e câncer da junção colorretal: análise da presença de lesões precoces microscópicas na periferia do câncer colorretal e correlação com a expressão da $\beta$-catenina e $\mathrm{Ki}-67$
}

\author{
Aberrant crypt foci and cancer of the colorectal junction: the correlation \\ between $\beta$-catenin/Ki-67 expression and the occurrence of early microscopic \\ secondary lesions surrounding periphery colorectal cancer
}

\author{
Daniel Cury Ogata ${ }^{1}$; Fernando Hintz Greca ${ }^{2}$; Murilo de Almeida luz ${ }^{3}$; Sérgio Ossamu loshil; ; \\ Flávio Daniel SaAvedra Tomasich, TCBC-PR ${ }^{5}$
}

\section{RE S U M O}

\begin{abstract}
Objetivo: Avaliar a presença de foco de criptas aberrantes (FCA) em mucosa macroscopicamente normal, localizada na periferia de um câncer colorretal (CCR) e correlacionar a progressão tumoral destes FCA para o CCR, por meio da expressão da $\beta$-catenina e o Ki-67. Métodos: Utilizou-se 21 espécimes cirúrgicos contendo adenocarcinoma de junção retossigmóide. Foram coletadas amostras localizadas a 1 e $5 \mathrm{~cm}$ proximal e distal ao tumor, quando possível, bem como um fragmento da neoplasia. Os FCA foram selecionados. Subseqüentemente foi realizado estudo imunoistoquímico com os anticorpos b-catenina e o Ki-67. Resultados: A expressão nuclear da b-catenina nos adenocarcinomas, revelou freqüência de $81 \%$. O Ki-67 apresentou a mesma freqüência. Apesar disso o coeficiente Kappa revelou fraca concordância entre estes anticorpos. Foram observados 20 FCA, sendo que 13 destes focos localizavam-se nas proximidades do tumor. Nenhum dos FCA apresentou expressão da $\beta$-catenina nuclear, tampouco para o Ki-67. Conclusão: Nas áreas situadas a $1 \mathrm{~cm}$ da neoplasia colorretal, foi observada maior concentração de FCA em relação às áreas situadas a $5 \mathrm{~cm}$ do tumor. No entanto, não se observou correlação entre a expressão da $\beta$-catenina e ki-67 nos colonócitos das criptas aberrantes das áreas estudadas, com as células neoplásicas do adenocarcinoma.
\end{abstract}

Descritores: Adenocarcinoma, $\beta$-catenina, Foco de criptas aberrantes.

\section{INTRODUÇÃO}

O câncer colorretal (CCR) é a quinta neoplasia maligna mais comum em homens e a quarta em mulheres. A faixa etária de maior incidência situa-se entre os 50 e 70 anos, todavia não é raro o surgimento deste tumor em pacientes mais jovens, abaixo dos 40 anos ${ }^{1}$.

O processo evolutivo do CCR envolve uma série de etapas que estão relacionados com o acúmulo de mutações genéticas ${ }^{2}$. Mutações nos genes $K$-ras e APC, por exemplo, têm importante papel na carcinogênese colorretal. $\mathrm{O}$ gene $A P C$ atua principalmente na regulação de uma proteína denominada b-catenina ${ }^{3}$. Esta proteína, cuja função é aderência celular, é degradada no citoplasma por meio de proteólise pelo complexo de ataque $A P C /$ axina/ GSK-3 $\beta$. A mutação do gene $A P C$ pode ativar uma via que dissolve o complexo de ataque. Com isso, a proteólise da b-catenina não ocorre e esta molécula torna-se estável no citoplasma, podendo posteriormente alcançar o núcleo. No núcleo, a $\beta$-catenina pode modular a expressão de vários genes alvos que favorecem a carcinogênese. Assim, a partir de um epitélio normal, dá-se início a proliferação celular, passando pela etapa de adenoma até carcinoma invasor ${ }^{4,5}$. Apesar do conhecido papel da $\beta$-catenina na carcinogênese do cólon, a identificação desta proteína no núcleo de células neoplásicas de adenocarcinoma não é constante $2,6,7$.

Recentemente foram observadas, utilizando-se um endoscópico de magnificação, criptas colônicas anormalmente alargadas, identificadas em cólon humano após serem coradas com azul de metileno. Em um paralelo, estas criptas tinham similaridade àquelas observadas em roedores, quando expostos ao azoximetano (AOM), um carcinógeno específico para cólon. A análise histológica destas lesões, mostrou alterações peculiares que, além do aumento destas criptas, vistas endoscopicamente, havia também espessamento epitelial, maior espaço peri-críptico e eventualmente, displasia9 ${ }^{9}$. Bird foi quem primeiro descre-

Trabalho realizado nos Departamentos de Cirurgia e Patologia Experimental da PUC-PR e Hospital Erasto Gaertner, apresentado como prérequisito para a obtenção do grau de Mestre em Cirurgia pela PUC-PR.

1. Médico Patologista do Hospital Erasto Gaertner; Mestre em Cirurgia pela PUCPR; 2. Professor Titular de Técnica Cirúrgica e Cirurgia Experimental da PUCPR Doutor em Cirurgia Experimental pela UNIFESP-EPM; 3. Cirurgião Oncológico do Hospital Erasto Gaertner; 4. Professor Titular de Patologia da PUCPR; 5. Cirurgião Oncológico do Hospital Erasto Gaertner. 
veu esta entidade, chamando-a de foco de criptas aberrantes (FCA), além de reconhecê-la como lesão precoce e precursora do CCR

Alguns autores acreditam que os FCA, ou pelo menos alguns deles, podem ser precursores do CCR. Em humanos, a maior concentração de CA coincidem justamente com as áreas mais distais do cólon, em que o CCR é mais freqüente, aliás, situação essa, também verificada em estudos animais, quando adenocarcinomas foram induzidos em cólon de ratos. O tamanho destas lesões tende aumentar com o tempo. A presença de displasia foi um marco na evolução destas lesões para a progressão neoplásica ${ }^{10-16}$.

As mutações dos genes APC e $K$-ras, alterações importantes observadas em pacientes com CCR, também foram identificadas em pacientes com FCA ${ }^{11}$. Contudo, a expressão nuclear da b-catenina em FCA é controversa. Alguns autores classificam as criptas que acumulam $\beta$-catenina nuclear como entidade distinta. Outros defendem a expressão nuclear desta proteína em FCA ${ }^{17-19}$

As alterações moleculares, os achados morfológicos e o padrão de crescimento têm contemplado a hipótese de que os FCA são lesões precursoras iniciais do CCR. Alguns autores sugerem que a tradicional seqüência adenoma-carcinoma na progressão tumoral do intestino grosso pode ser estendida para a seqüência FCA-adenomacarcinoma?.

A natureza pré neoplásica dos FCA parece já estar bem estabelecida. No entanto, estudos que mostrassem a distribuição, a densidade e a dimensão destas criptas no cólon de populações de risco, constituiriam importante contribuição na profilaxia do CCR ${ }^{11}$. O objetivo deste trabalho é em primeiro lugar, avaliar a presença de FCA em mucosa macroscopicamente normal, localizada na periferia de um $C C R$ e está relacionada à progressão tumoral destes FCA para o CCR, por meio da expressão da b-catenina e o Ki67.

\section{MÉTODOS}

\section{SELEÇÃO DOS CASOS}

Para a realização desta pesquisa foram utilizados 21 espécimes cirúrgicos de pacientes submetidos a retossigmoidectomia, com diagnóstico prévio de adenocarcinoma de junção colorretal. Esta coleta procedeu-se durante o período de novembro de 2006 a julho de 2007, no departamento de Anatomia Patológica do Hospital Erasto Gaertner.

Após aprovação no Comitê de Ética em Pesquisa, foi iniciada a fase de coleta de materiais. Utilizando um cilindro de aço inoxidável com área cortante de $1 \mathrm{~cm}^{2}$, foram retirados de três a quatro fragmentos de mucosa macroscopicamente normal (dependendo do diâmetro do órgão), situados a $1 \mathrm{~cm}$ e $5 \mathrm{~cm}$ do bordo inferior e superior do tumor, bem como um fragmento da própria neoplasia (Figura 1). Todo o material coletado foi submetido a processamento histológico, sendo as lâminas coradas com coloração de rotina. A análise histológica da mucosa macroscopicamente normal foi feita com o intuito de identificar FCA. Estes foram identificados pelo alargamento das criptas, aumento do espaço peri-críptico e espessamento epitelial Figura 2A. A displasia nestes focos era caracterizada por células hipercromáticas, núcleos alongados, estratificação nuclear e depleção de mucina (Figura 2B).

Com a finalidade de minimizar custos com a imunoistoquímica, realizou-se um método denominado tissue microarray (TMA). Este método consiste em confeccionar um bloco de parafina com representações histológicas multi-amostrais. Para isso, foram selecionados um fragmento com 2 mm de diâmetro de cada neoplasia, bem como um fragmento com as mesmas dimensões de cada caso que continha FCA.

Os blocos de TMA foram cortados à espessura de $4 \mu \mathrm{m}$, sendo confeccionadas três lâminas, uma delas corada em hematoxilina-eosina e as restantes submetidas ao processamento imunoistoquímico.

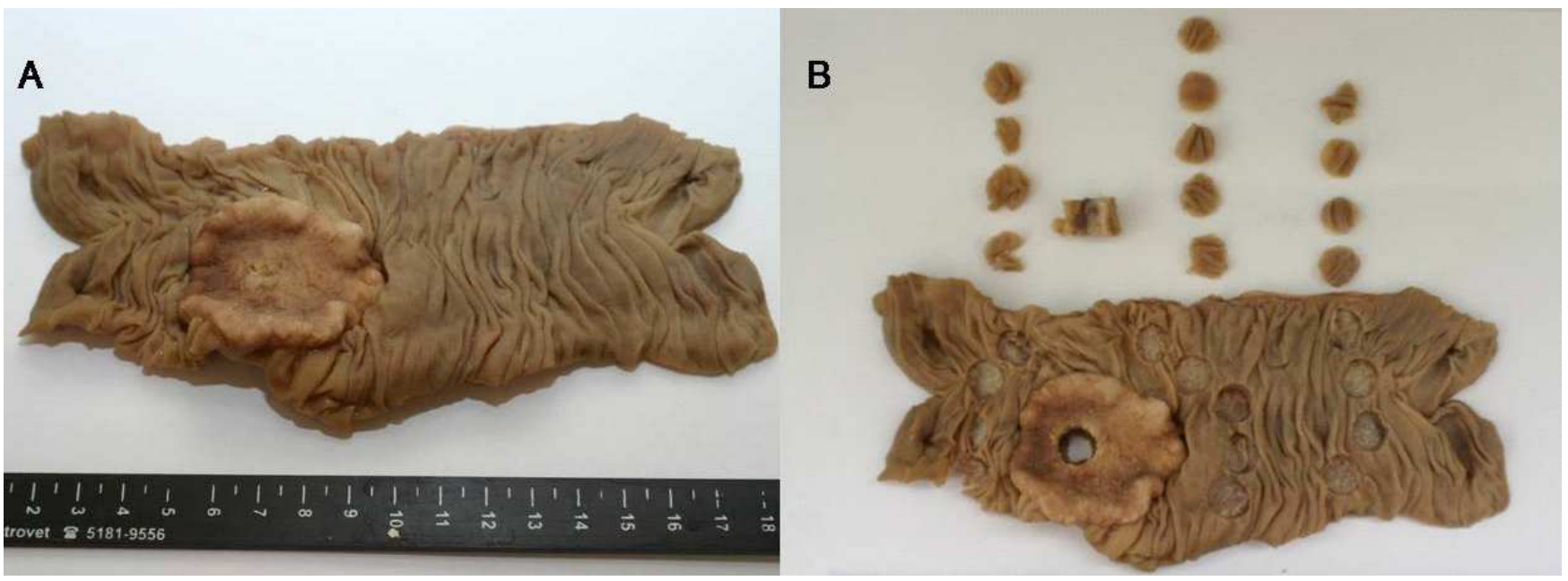

Figura 1 - Segmento de intestino grosso, aberto longitudinalmente e evidenciando neoplasia colorretal (A); O mesmo espécime cirúrgico da figura 3 após a coleta dos fragmentos a 1 e $5 \mathrm{~cm}$ proximais da lesão e 1 e 5 em distais da lesão (B). 


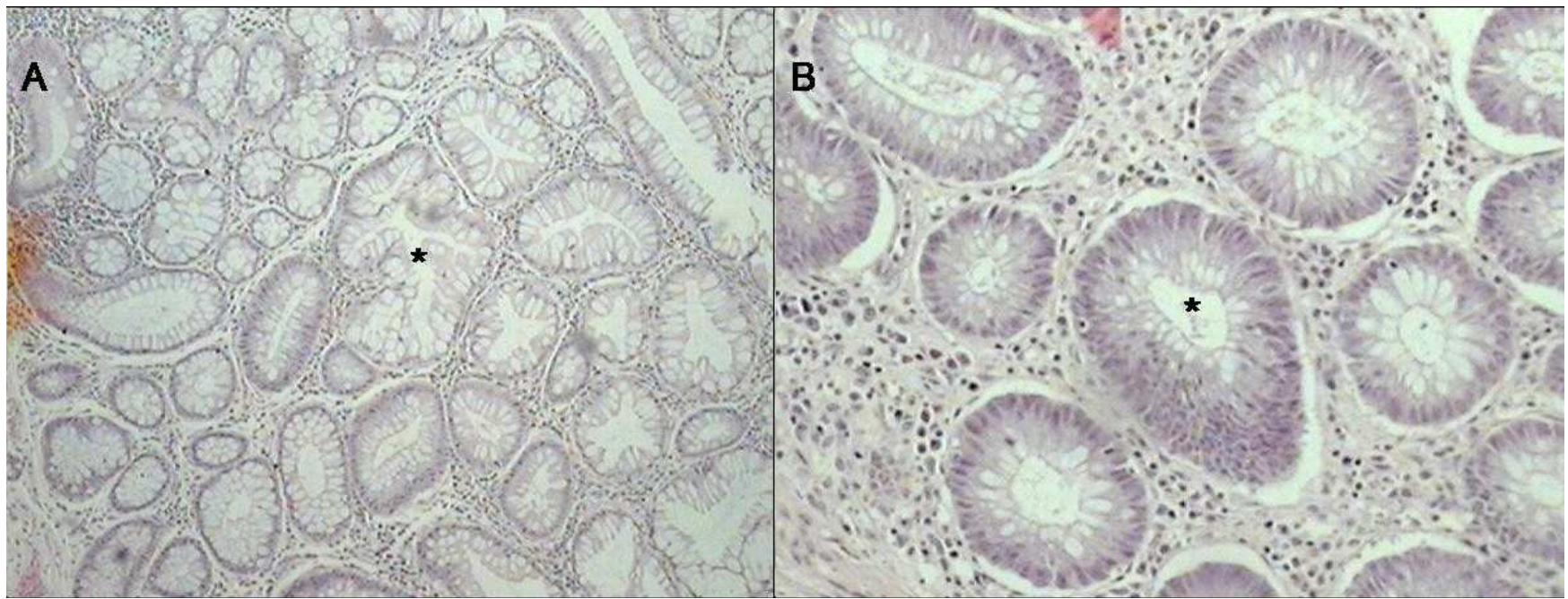

Figura 2 - Fotomicrografia de cólon, mostrando cripta aumentada de tamanho, lúmen com aspecto de dente de serra e células caliciformes hiperdistendidas (asterisco) (HE 200x) (A); Fotomicrografia revelando cripta aberrante com redução na produção de mucina, além de pseudoestratificação (asterisco) (HE 400x) (B).

\section{ESTUDO IMUNOISTOQUÍMICO}

As lâminas de TMA foram submetidas ao processo de imunohistoquímica pela técnica da imunoperoxidase. Esta permite a pesquisa de antígenos específicos em material parafinado. O protocolo apresenta fases distintas como deparafinização e re-hidratação, primeiro e segundo bloqueio da peroxidase endógena, recuperação antigênica, incubação com anticorpo primário e secundário, revelação, contra-coloraçãa, desidratação, clarificação e montagem. A deparafinização é realizada com xilol quente à $37^{\circ} \mathrm{C}$ e a re-hidratação com banhos sucessivos de álcool, em concentrações decrescentes, conforme técnicas convencionais. Todos os casos foram corados em duplicata, utilizando-se uma lâmina como controle negativo, na qual não será adicionado o anticorpo primário.

O primeiro bloqueio da peroxidase endógena, realizado antes da recuperação antigênica, é feito com álcool metílico mais peróxido de hidrogênio na proporção 1:10. Para o segundo bloqueio, que ocorrerá após a recuperação, será utilizado água destilada e peróxido de hidrogênio.

Os anticorpos utilizados foram da marca

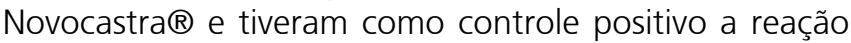
com amígdala de rato, apresentando as seguintes especificações (classe e diluições): $\beta$-catenina - IgG classe 2a, na diluição 1:800; Ki-67 clone MIB-1- IgG classe 1, na diluição 1:50.

A incubação com os anticorpos ( $\beta$-catenina e Ki67) nas diluições determinadas, tem duração de uma hora, em câmara úmida e temperatura ambiente. O anticorpo secundário, associado ao polímero dextrana (Envision Dual link Dako®) foi incubado com o material por 30 minutos, também em temperatura ambiente.

Para revelação é adicionado o complexo DAB + substrato sobre as lâminas, por três minutos, conforme técnicas convencionais.

A contra-coloração foi realizada com hematoxilina de Mayer por 1 minuto, seguida de desidra- tação com banhos de álcool etílico 100\% e da clarificação com xilol em temperatura ambiente.

Para a montagem das lâminas foi utilizado Bálsamo do Canadá, em técnica similar à montagem de lâminas convencionais.

A análise da reação dos anticorpos foi qualitativa, analisando apenas a positividade ou negatividade para os anticorpos utilizados.

\section{ANÁLISE ESTATISTICA}

Para a análise estatística, foram utilizadas a descrição das variáveis e a aferição do coeficiente de concordância Kappa, para avaliar se existia correlação entre a imunorreação dos anticorpos.

\section{RESULTADOS}

Foram analisados 21 casos com diagnóstico prévio de câncer de junção colorretal, com idades variando de 36 anos a 82 anos (média de 59,7 anos), sendo 11 mulheres e 10 homens. Todos os tipos histológicos eram de adenocarcinoma usual.

A expressão da b-catenina nuclear foi observada em 17 dos 21 adenocarcinomas, atingindo uma freqüência de $81 \%$ (Figura 3A).

O Ki-67 atendeu esta mesma distribuição, em que 17 dos 21 adenocarcinomas obtiveram expressão (Figura 3B). Apesar disso o coeficiente de concordância (Kappa) com a expressão nuclear da b-catenina com este anticorpo foi de 0,38 , revelando fraca concordância.

Em relação aos FCA, foram observados 20, que atenderam a seguinte distribuição: oito localizados à $1 \mathrm{~cm}$ proximal ao tumor, cinco localizados à $5 \mathrm{~cm}$ proximal ao tumor, cinco localizados à $1 \mathrm{~cm}$ distal ao tumor e dois localizados à $5 \mathrm{~cm}$ distal ao tumor (Tabela 1). A displasia foi observada em apenas dois casos, localizados a $1 \mathrm{~cm}$ proximal e outro a $1 \mathrm{~cm}$ distal ao tumor (Figura 4). 


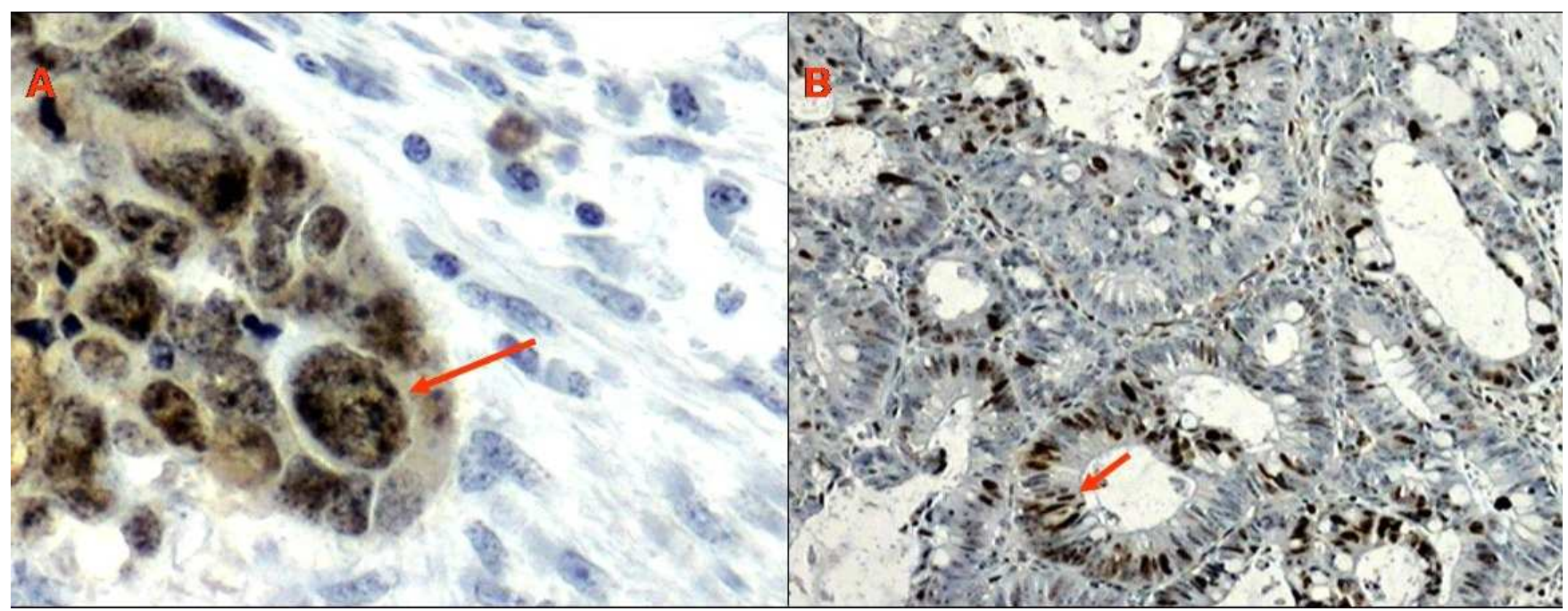

Figura 3 - Fotomicrografia realçando imunorreatividade nuclear (coloração acastanhada - seta) para $\beta$-catenina 1000 (x) (A); Fotomicrografia mostrando imunorreatividade nuclear (coloração acastanhada - seta) para o Ki-67 (Ki-67 200x.) (B).

Presença de FCA em relação à distância do tumor

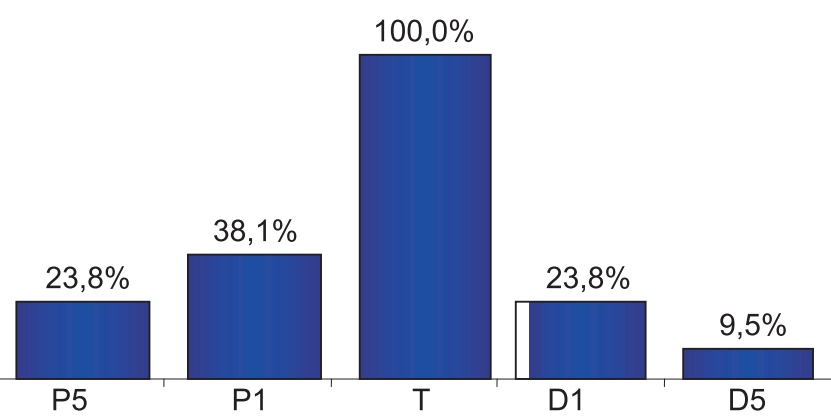

Figura 4 - Distribuição dos FCA ao redor do tumor. ( $T$ = tumor; $P 1=1$ em proximal ao tumor; $P 5=5 \mathrm{~cm}$ proximais ao tumor, $D 1=1$ em distal ao tumor; $D 5=5 \mathrm{~cm}$ distais ao tumor).

Nenhum dos FCA apresentou expressão dos anticorpos $\beta$-catenina nuclear e Ki-67.

\section{DISCUSSÃO}

O sul do país é a região com maior incidência de CCR no Brasil, sendo encontrado em 15,09 a 27,68/100000 homens e 16,51 a 28,07/100000 mulheres, dependendo do estado. A proporção homens: mulheres foi muito próximo, refletindo os resultados deste trabalho, em que foram observados 1,1 mulheres para cada homem. A maior incidência dos casos ocorre na faixa etária situada entre 50 e 70 anos $^{1}$.

O desenvolvimento e a progressão do $C C R$, assim como em outros cânceres, passam por etapas que vão desde um epitélio normal, passando por um estado hiperproliferativo, chegando à forma de um adenoma até tornar-se um carcinoma francamente invasor. Isto denomina-se progressão tumoral ${ }^{13}$.

Recentemente foram observadas criptas anormalmente alargadas, com espessamento epitelial e aumento do espaço peri-críptico em ratos expostos a carcinógenos específicos para cólon. Tais criptas agrupavam-se em focos e foram chamadas de FCA ${ }^{8}$. Essas lesões são provavelmente o evento mais precoce da progressão tumoral dos cólons. Os FCA foram freqüentes em indivíduos com doenças de risco para o desenvolvimento do CCR, como, por exemplo, adenomas. Observou-se também freqüência menor em pacientes portadores de doenças não relacionadas ao CCR, ou seja, que não carregam este risco como, por exemplo, a diverticulose ${ }^{11,15,16}$. A localização de tais criptas coincide com a dos CCR, portanto, na junção retossigmóide, reforçando o seu caráter precursor de malignidade ${ }^{14}$. Muitos estudos têm tentado correlacionar alterações progressivas nos FCA, como por exemplo, a displasia na sua evolução para o adenocarcinoma ${ }^{10-16}$. As alterações genéticas importantes no cenário da progressão carcinogênica para este tipo de

Tabela 1 - Localização dos FCA.

\begin{tabular}{lcc}
\hline Região & Frequência de criptas aberrantes & Percentual \\
\hline Proximal a $5 \mathrm{~cm}$ & 5 & $23,8 \%$ \\
Proximal a $1 \mathrm{~cm}$ & 8 & $38,1 \%$ \\
No tumor & 21 & $100 \%$ \\
Distal a $1 \mathrm{~cm}$ & 5 & $23,8 \%$ \\
Distal a $5 \mathrm{~cm}$ & 2 & $9,5 \%$ \\
\hline
\end{tabular}


neoplasia, também foram identificadas nos FCA, como por exemplo, as mutações que ocorrem nos genes $A P C$ e $\mathrm{K}$-ras. As mutações no gene $A P C$ são provavelmente o evento mais precoce em CCR. Sua presença tem sido descrita desde em adenomas macroscópicos até lesões menores com 0,3 cm de diâmetro. No entanto, mutações no gene $A P C$ não têm sido identificadas nos FCA em humanos $^{3}$. Pretlow et al. ${ }^{20}$ realizaram estudo, utilizando ratos com mutação induzida no gene $A P C$ e sugeriram que a mutação deste gene está implicada na iniciação dos FCA, mas não na progressão. Já em estudos prévios, foram observadas mutações nos genes ras em ratos e uma pequena série de FCA em humanos ${ }^{3}$.

\section{RELAÇÃO COM A $\beta$-catenina}

As células epiteliais normais deixam de se multiplicar assim que estabelecem contato com a célula vizinha. Isto é conhecido como inibição de contato. Elas aderem-se umas às outras por meio de moléculas de adesão celular. Nas células tumorais, esta comunicação intercelular pode estar interrompida, devido à expressão defeituosa de alguns genes. Esta situação conduz as células tumorais a exibir um crescimento "anti-social" destrutivo ${ }^{21}$

A catenina é uma família de genes, cujo primeiro integrante descrito, definido como $\alpha$-catenina, tem a função de ligar a molécula caderina ao citoesqueleto, resultando em aderência celular ${ }^{21}$. A $\beta$-catenina um outro representante desta família, com função semelhante, responsável em se ligar a outros tipos de proteína, não apenas a $\alpha$-catenina e a actina, mas também a axina, caderina, fatores de transcrição e ligantes Wnt. Em células normais, a $\beta$-catenina é responsável pela adesão celular e quando encontra-se livre no citoplasma é fosforilada e degradada pelo complexo APC/Axina/GSK $3 \beta^{4-6,21}$. 0 gene $A P C$ é o gene supressor de tumor. A axina é um gene que age concomitantemente com o glicogênio sintetase kinase 3 (GSK-3). Esta última é uma proteína que media a adição das moléculas de fosfato e trabalha com a via de sinalização Wnt na fosforilação da $\beta$ catenina ${ }^{4}$. Na ausência dos ligantes Wnt, as proteínas APC e Axina seqüestram a $\beta$-catenina, permitindo que a caseína quinase 1 (CK-1) fosforile o seu $\mathrm{N}$ terminal em Seronina/ Treonina. Após isso, ocorre na seqüência a ubiquitinização e condução da $\beta$-catenina a proteólise pelo complexo de ataque. Alguns estudos sugerem que a ativação da via da $\beta$-catenina tem sido responsável pela iniciação da maioria dos cânceres colorretal. Em mais de $80 \%$ dos pacientes com esta neoplasia, o gene APC é inativado por mutações, resultando em ativação dos ligantes Wnt. Estes ligantes unem-se a proteína trans-membrana da família Frizzled, ativando outra proteína, denominada Dishevelled. Esta inibe o complexo APC/Axina/GSK 3 $\beta$, fazendo com que a molécula da $\beta$-catenina não sofra proteólise. Assim, esta molécula torna-se estável, acumula-se no citoplasma e posteriormente alcança o núcleo, transcrevendo subseqüentemente genes alvos. Esta programação carcinogênica culmina na transcrição de diversos genes alvos da via Wnt ${ }^{5,22}$ câncer colorretal e correlação com a expressão da $\beta$-catenina e Ki-67

\section{$\beta$-catenina E FCA}

Yamada et al realizaram estudo experimental com ratos, administrando AOM para indução de CA. Eles utilizaram endoscópio de magnificação e observaram dois tipos de criptas. O primeiro tipo lembrava endoscopicamente FCA, sendo distinguida pelo seu tamanho aumentado, espessamento epitelial e aumento do espaço peri-criptico. O segundo tipo de criptas alteradas não tinha aparência de FCA, devido ao seu tamanho reduzido. Foram realizados estudos imunoistoquímicos destas lesões, que detectaram super expressão da $\beta$-catenina citoplasmática em 13 de 15 criptas. Também observou-se em quase todos os casos, localização anômala da $\beta$-catenina no núcleo. Estas lesões foram denominadas "criptas com acúmulo de b-catenina", sendo enquadradas como entidade distinta. Naquelas criptas semelhantes aos FCA, a expressividade da $\beta$-catenina não revelou acúmulo citoplasmático, tampouco translocação em direção ao núcleo ${ }^{17,18}$.

Para Pretlow e Bird ${ }^{19}$, os resultados de Yamada et $a l^{17}$ são controversos. Os autores questionaram o fato do grupo "criptas com acúmulo de $\beta$-catenina" ser uma entidade independente dos FCA. Segundo esses autores, as criptas com acúmulo de $\beta$-catenina têm características semelhantes a um subgrupo de FCA, que inclui a maioria dos FCA com displasia. Pretlow e Bird ${ }^{19}$ referiram ainda, que as preparações "em face", ou seja, com a superfície luminal voltada para baixo, podiam mostrar FCA em diferentes níveis de secção histológica e tal situação poderia explicar o tamanho reduzido nas criptas observadas.

Em nosso estudo, esperava-se expressão nuclear da $\beta$-catenina tanto nos FCA como nos respectivos adenocarcinomas. Esta expressividade era esperada pelo menos nos casos em que existia displasia, já que este é um forte preditor morfológico de pré-malignidade. Esta positividade nuclear concomitante poderia indicar uma via molecular comum, que teria conduzido os FCA para a transformação maligna. No entanto, nenhum FCA expressou a $\beta$-catenina no núcleo. Esta situação poderia fortalecer a teoria de Yamada et al, que rotularam as criptas com acúmulo de $\beta$-catenina como entidade distinta. Ou seja, sabendo-se da correlação dos FCA como lesões precursoras do CCR, a falta de acúmulo da $\beta$-catenina nuclear nos colonócitos das $C A$, poderia favorecer realmente a existência de dois tipos de criptas, conforme postulado por Yamada et $a{ }^{17}$. No entanto, Pretlow e Bird ${ }^{19}$ quando rebateram esta teoria, referiram as criptas com acúmulo de $\beta$-catenina como um subtipo de FCA com displasia. Sendo assim, não é possível separar estas criptas em dois grupos com os dados desta pesquisa, pois foram observados apenas dois casos de FCA com displasia, tornando-os estatisticamente insignificantes para este tipo de afirmação.

\section{$\beta$-catenina E CCR}

A expressão nuclear deste anticorpo foi extremamente variável na literatura. Enquanto Bondi et a/ ${ }^{7}$ encontraram expressão no núcleo dos tumores em apenas $22,2 \%$ dos seus casos, Kim et al ${ }^{6}$ obtiveram $40,3 \%$ de positividade, Chen et al 82,3\% ${ }^{2}$ e Kawada et al ${ }^{23} 70 \%$. 
Nosso estudo revelou dados muito próximos ao de Chen et $a l^{2}$, com freqüência de $81 \%$. No entanto, todas estas pesquisas foram realizadas comparando a expressão da $\beta$ catenina, com outras proteínas implicadas em um determinado passo da via carcinogênica. Foram feitos comparativos com o c-myc 2,7, proteína atuante na transdução de sinais, o Pin1, cuja função é regular a ciclina D1, que por sua vez controla o início e a progressão do ciclo celular e por último ${ }^{6}$, o STAT3, que é um ativador de sinal e transdutor de sinais ${ }^{23}$. Não foi encontrado nenhum trabalho correlacionando a expressão da $\beta$-catenina nuclear nos colonócitos dos FCA com os respectivos colonócitos dos adenocarcinomas, semelhante ao modelo experimental realizado no presente estudo. Outra situação que poderia alterar os resultados desta pesquisa foi o tamanho da amostra. Enquanto Kim et al. ${ }^{6}$ e Bondi et al. ${ }^{7}$ utilizaram respectivamente, 124 e 162 casos, Chen et al. ${ }^{2}$ utilizaram 85 pacientes e Kawada et al.23, 90 indivíduos. Nosso estudo envolveu apenas 21 casos. Sendo assim, pode-se supor que o aumento da amostragem poderia alterar a freqüência. Outro dado que pode explicar a ampla variação de resultados encontrados na literatura foi postulado por Yang et al ${ }^{4}$. Segundo estes autores, os mecanismos da função do $A P C$ em regular a $\beta$-catenina são mais complicados do que se costumava pensar. No estudo realizado por esses autores, foram obtidos dados que sugeriram que a degradação da b-catenina era feita por domínios distintos e mecanismos moleculares separados. Observou-se em seus experimentos que o gene $A P C$, cuja maior função é regular a $\beta$ catenina, quando mutado, bloqueava o complexo de ataque, responsável pela fosforilação desta proteína. Apesar do fato da $\beta$-catenina ter sua degradação inibida nas células tumorais por meio deste mecanismo, ainda observou-se algum grau de fosforilação da $\beta$-catenina. Com isso, os autores partiram da hipótese que as células tumorais com alto nível de $\beta$-catenina, podem ter um mecanismo de fosforilação independente do $A P C$. Nas células com o $A P C$ mutante, o índice de fosforilação e degradação da $\beta$ catenina é menor que o de síntese, podendo levar ao acúmulo desta proteína no citoplasma e posteriormente no núcleo. Sendo assim, a discrepância nos resultados obtidos na literatura mundial, podem ter relação com os diversos mecanismos responsáveis pelo controle da degradação e síntese da $\beta$-catenina.

Nas áreas situadas a $1 \mathrm{~cm}$ da neoplasia colorretal, foi observada maior concentração de FCA em relação às áreas situadas a $5 \mathrm{~cm}$ do tumor. No entanto não se observou correlação entre a expressão da $\beta$-catenina e ki-67 nos colonócitos das criptas aberrantes das áreas estudadas, com as células neoplásicas dos adenocarcinomas.

\section{A $B$ S S T}

Objective: To evaluate the occurrence of aberrant crypt foci (ACF) in macroscopic normal mucosa surrounding colorectal cancers (CRC); additionally, analyze tumor progression from ACF to CRC by means of $\beta$-catenin and Ki-67 expression. Methods: Twentyone surgical specimens showing colorectal junction adenocarcinoma were included. Macroscopic normal mucosa proximal and distal to the primary tumor was sampled at a distance of 1 and $5 \mathrm{~cm}$ in both sides. A primary tumor sample was also retrieved. Eventually, ACF's were selected and immunohistochemical analysis of $\beta$-catenin and Ki-67 were carried out. Results: Among all adenocarcinoma samples, the frequency of positive â-catenin nuclear expression was $81 \%$. The Ki-67 expression demonstrated the same percentage of positivity as did $\beta$-catenin. However, the Kappa coefficient showed weak relationship between those two antibodies. Among 20 ACF's analyzed, 13 were located close $(1 \mathrm{~cm})$ to the tumor. None of the ACF's demonstrated nuclear expression of $\beta$-catenin or Ki67. Conclusion: Higher concentrations of ACF's were observed in colonic mucosa at a distance of $1 \mathrm{~cm}$ compared to samples at 5 $\mathrm{cm}$ from the primary $C R C$. However, we could not demonstrate positive correlation between colonocytes $\beta$-catenin expression and the occurrence of ACF's.

Key words: Adenocarcinoma. $\beta$-Catenin. Aberrant crypt foci.

\section{REFERÊNCIAS}

1. Ministério da Saúde. Incidência de Câncer no Brasil. Internet. Disponível: http:www.inca.gov.br/estimativa/2006/. Acesso em: 07 set. 2007

2. Chen WC, Lin MS, Zhang BF, Fang J, Zhou Q, Hu Y, et al. Survey of molecular profiling during human colon cancer development and progression by immunohistochemical staining on tissue microarray. World J Gastroenterol. 2007; 13(5):699-708.

3. Smith AJ, Stern HS, Penner M, Hay K, Mitri A, Bapat BV, et al. Somatic APC and K-ras codon 12 mutations in aberrant crypt foci from human colons. Cancer Res. 1994; (54):5527-30.

4. Yang J, Zhang W, Evans PM, Chen X, He X, Liu C. Adenomatous Polyposis Coli (APC) differentially regulates â-catenin phosphorylation and ubiquitination in colon. J Biol Chem. 2006; 281(26):17751-7. Epub 2006 May 3.
5. Huang D, Du X. Crosstalk between tumor cells and microenvironment via Wnt pathway in colorectal cancer dissemination. World J Gastroenterol. 2008; 14(12):1823-7.

6. Kim CJ, Cho YG, Park YG, Nam SW, Kim SY, Lee SH et al. Pin1 overexpression in colorectal cancer and its correlation with aberrant $\beta$-catenin expression. World J Gastroenterol. 2005;11(32):5006-9.

7. Bondi J, Bukholm G, Nesland JM, Bukholm IR. Expression of nonmembranous â-catenin and g-catenin, c-Myc and Cyclin D1 in relation to patient outcome in human colon adenocarcinomas. APMIS. 2004; 112(1):49-56.

8. Bird RP. Observations and quantification of aberrant crypts in the murine colon treated with a colon carcinogen: preliminary findings. Cancer Lett. 1987; 37(2):147-51.

9. Hurlstone DP, Cross SS. Role of aberrant crypt foci detected using high-magnification-chromoscopy colonoscopy in human colorectal carcinogenesis. J Gastroenterol Hepatol. 2005;20(2):173-81. 
10. Siu IM, Pretlow TG, Amini SB, Pretlow TP. Identification of dysplasia in human colonic aberrant crypt foci. Am J Pathol 1997; 150(5):1805-13.

11. Roncucci L, Modica S, Pedroni M, Tamassia MG, Ghidoni M, Losi L et al. Aberrant crypt foci in patients with colorectal cancer. $\mathrm{Br} J$ Cancer. 1998; 77(12): 2343-8.

12. McLellan EA, Medline A, Bird RP. Sequential analyses of the growth and morphological characteristics of aberrants crypts foci: putative preneoplastic lesions. Cancer Res. 1991;51(19): 5270-4.

13. Shpitz B, Hay K, Medline A, Bruce WR, Bull SB, Gallinger S et al. Natural history of aberrant crypt foci. A surgical approach. Dis Colon Rectum. 1996; 39(7):763-7.

14. Nucci MR, Robinson CR, Longo P, Campbell P, Hamilton SR. Phenotypic and genothypic characteristics of aberrants crypts foci in human colorectal mucosa. Hum Pathol. 1997;28(12):1396-407.

15. Takayama TT, Katsuki S, Takahashi Y, Ohi M, Nojori S, Sakamaki $S$ et al. Aberrant crypt foci of the colon as precursors of adenoma and cancer. N Engl J Med. 1998; 339(18):1277-84.

16. Nascimbeni R, Villanacci V, Mariani PP, Di Betta E, Ghirardi M, Donato $F$ et al. Aberrant crypt foci in the human colon: frequency and histologic patterns in patients with colorectal cancer or diverticular disease. Am J Surg Pathol. 1999;23(10):1256-63.

17. Yamada Y, Yoshimi N, Hirose Y, Kawabata K, Matsunaga K, Shimitzu $M$ et al. Frequent â-catenin gene mutations and accumulatiosn of the protein in the putative preneoplastic lesions lacking macroscopic aberrant crypt foci appearance, in rat colon carcinogenesis. Cancer Res. 2000; 60(13):3323-7.

18. Yamada Y, Mori H. Pre-cacerous lesions for colorectal cancers in rodents: a new concept. Carcinogenesis. 2003;24(6):1015-9. Epub 2003 Mar 28.

19. Pretlow TP e Bird RP. Correspondence re: Y Yamada et al., Frequent $\beta$-catenin Gene mutations and accumulations of the protein in the putative preneoplastic lesions lacking macroscopic aberrant crypt foci appearance, in rat colon carcinogenesis. Cancer Res. 2000;60(13):3323-7; and Sequential analysis of morphological and biological properties of â-catenin-carcinogenesis. Cancer Res. 2001;61(5):1874-8.

20. Pretlow TP, Edelmann W, Kucherlapati R, Pretlow TG, Augenlicht LH. Spontaneous aberrant crypt foci in Apc1638N Mice with a mutant Apc allele. Am J Pathol. 2003; 163(5):1757-63.

21. Riede UN, Werner M. Color Atlas of Pathology. Pathologic principles, associated diseases, sequelae. $1^{\text {st }}$ ed. New York: Thieme; 2004.

22. Gregorieff $A$, Clevers $H$. Wnt signaling in the intestinal epithelium: from endoderm to cancer. Genes Dev. 2005;19(8):877-90.

23. Kawada M, Seno H, Uenoyama Y, Sawabu T, Kanda N, Fukui H et al. Signal transducers and activators of transcription 3 activation is involved in nuclear accumulation of $\beta$-catenin in colorectal cancer. Cancer Res. 2006; 66(6):2913-7.

Recebido em 26/01/2009

Aceito para publicação em 31/04/2009

Conflito de interesse: nenhum

Fonte de financiamento: nenhuma

\section{Como citar esse artigo:}

Ogata DC, Greca FH, Luz MA, Ioshii SO, Tomasich FDS. Foco de criptas aberrantes e câncer da junção colorretal: análise da presença de lesões precoces microscópicas na periferia do câncer colorretal e correlação com a expressão da â-catenina e ki-67. Rev Col Bras Cir. [periódico na Internet] 2010; 37(2). Disponível em URL: http://www.scielo.br/ rcbc

\section{Endereço para correspondência:}

Daniel Cury Ogata

E-mail: daniel.ogata@gmail.com 